\title{
Provisions for the Formation of a Maritime Shipping Company's Competitiveness Management System
}

\begin{abstract}
Submitted 05/02/19, 1st revision 17/02/19, 2nd rervision 15/04/19, accepted 25/05/19
Volynchikov I.B. ${ }^{1}$, Timchenko T.N. ${ }^{2}$

Abstract:

Purpose: The aim of this paper is to build up the competitiveness management system for a maritime shipping company. Freight market is a very specific market, which includes high competitiveness and has no differences between services delivered by competitors. As a result, shipping companies are unable to use price-based and quality-based competitive approach and should use unusual competitive behavior.

Design/Methodology/Approach: To buid up the competitiveness management system it is necessary to describe its features and properties to get such system integrated into current company's business processes. Authors intended to describe the phased procedure for competitiveness management; the methodical approach for constructing such a system and features of the competitiveness management system.

Findings: Every goal set by the authors, was reached and presented as a scheme and as a detailed text description of the scheme. This makes building up the competitiveness management system and its implementation much easier.

Practical Implications: Results of the present research may be implemented into management practices in order to improve and increase the effectiveness of maritime shipping companies' competitiveness on the high competitive freight market. System can be tweaked to suit any shipping business - it is good and effective as for small one-vessel companies as well as for large corporations.

Originality/Value: The main contribution of this study is the description of the methodical approach to build specific, shipping companies 'oriented, competitiveness management system, which is partially similar to usual competitiveness management approach, although it has significant differences caused by the specifics of shipping.
\end{abstract}

Keywords: Competitiveness, management, shipping companies, freight market.

JEL Codes: B41, F23, R40, R49.

Paper Type: Research article in Special Issue dedicated to Russian Economy.

Section 3: Management Systems.

\footnotetext{
${ }^{1}$ Senior lecturer of "Economic theory, Economics and Management" Chair, Federal State Educational Institution of higher education "Admiral Ushakov State Maritime University", postal05@mail.ru

${ }^{2}$ Candidate of Science (Economics), Associate Professor of the Department of Transportation Organization and Transport Management of Federal State Educational Institution of higher education "Admiral Ushakov State Maritime University”, timchenkomga@gmail.com
} 


\section{Introduction}

Currently, shipping companies are working in a very dynamic competitive market with other domestic and foreign carriers, in an oversupply tonnage in the freight market and a decrease in cargo volumes (Ha and Seo, 2017). In addition, the results of their activities are influenced by numerous factors of the internal and external environment. The lack of differentiation of maritime merchant fleet products within the chosen market niche, slight variation in freight rates within each class and size of vessels minimizes the choice of competitive strategies. Carrying out its activities in a highly competitive market environment, maritime shipping companies which wish to remain in demand in the transport services market are forced to ensure the highest possible customer satisfaction and strive to improve the efficiency of their own business processes. Improving the competitiveness of maritime shipping companies that produce the same type of product at the same market price and which are unable to accumulate it for realization in more favorable periods and depends largely on the efficiency and quality of commercial and technical management.

The analysis of the activities of maritime shipping companies to increase their competitiveness revealed the need to develop scientifically based methodological guidelines for the development of a competitiveness management system to develop management solutions aimed at improving competitive positions (Thalassinos et al., 2011).

The methodological basis for the development of the concept of competitiveness management were the modern methods of accounting and control, allowing in a semi-automatic mode to collect and process data on all areas of the company. Usually, such information accumulates on the level of individual company units, but aggregated they can be useful to increase the level of the competitiveness of the company. In accordance with the logic of development, the concept of building a competitive management system for a maritime shipping company relies on a certain number of subsystems corresponding to the directions of its practical implementation, which ensure the stable operation of such a system.

\section{Methodical Provisions}

According to the authors, the management of the competitiveness of the maritime shipping company should be carried out in stages and includes: the formation of theoretical and methodological provisions of the maritime shipping company competitiveness management system (MSC CMS); system implementation in the company; assessment of the competitiveness of the maritime shipping company; managing impact on the company's business processes.

The process of managing the competitiveness of the maritime shipping company in graphical form, in the form of a phased process is placed below in Figure 1: 
Figure 1. The Phased Procedure For Managing The Competitiveness Of The Maritime Shipping Company ${ }^{3}$

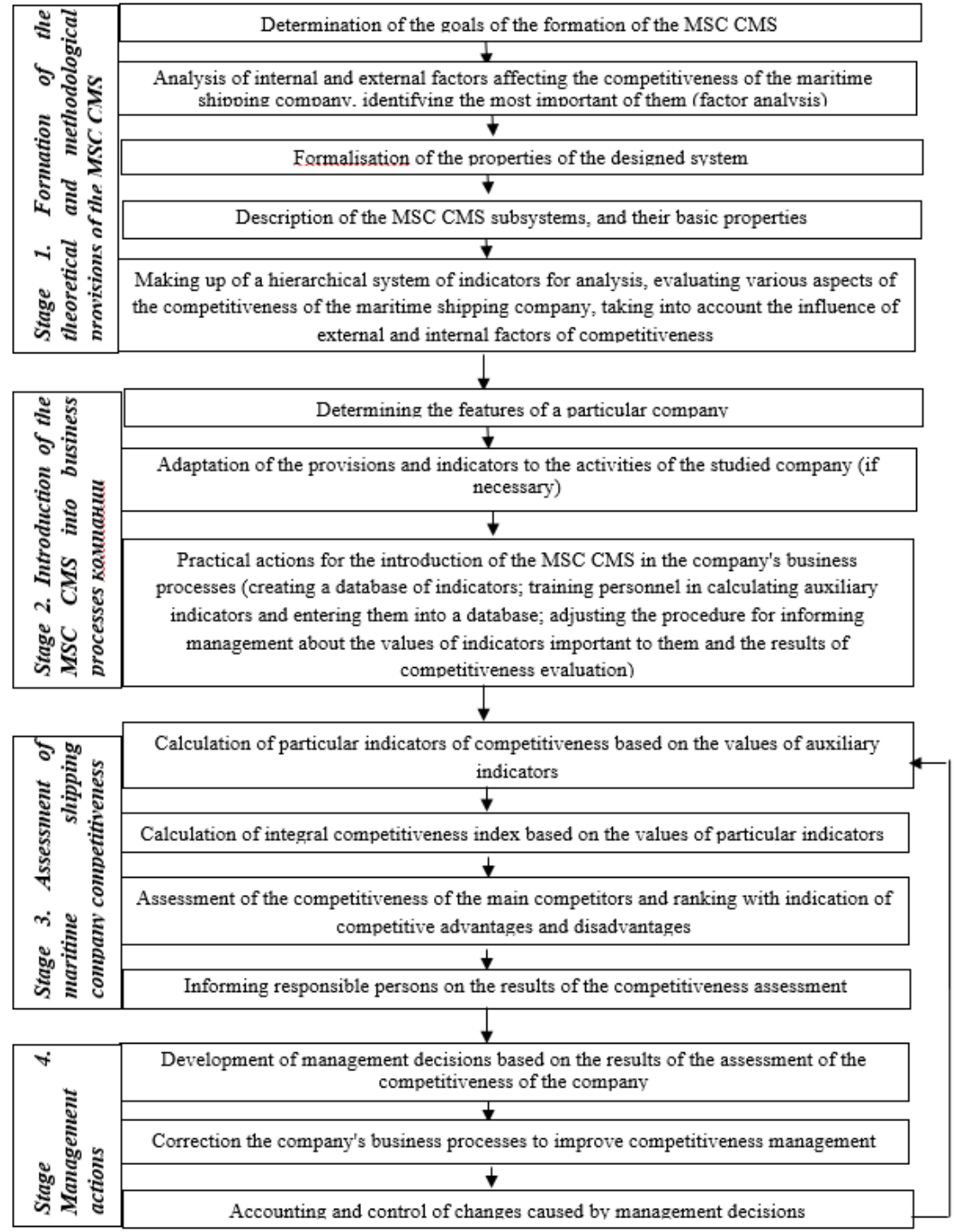

The MSC CMS, being a large socio-economic system with many diverse functions, has a large number of elements and subsystems and a complex hierarchical structure. The subsystems are aimed at maintaining the functionality and practical applicability of the MSC CMS. As with any complex structure, the MSC CMS for normal activities requires a certain combination of baseline conditions. To conduct a scientific research, clearly formalized methods of collecting, accumulating and

${ }^{3}$ Compiled by the authors on the materials of the study 
analyzing information are needed, as well as methods for conducting such an analysis and a clear vision of the steps necessary to achieve the goal. Since the application of the system is planned on the basis of enterprises with a wellestablished business process, it is necessary to make some changes in the organizational and personnel structure of the company in order to provide the MS CMS with sources of information and executors of the intermediate stages of analysis. In addition, in the course of the study, it is necessary to rely on legislation in order to bring the company's activities in line with the requirements of this legislation, as well as with the aim of cutting off in advance competitiveness methods that are expressly prohibited by existing laws (Figure 2).

Figure 2. Methodical Approach to the Formation of the MSC CMS

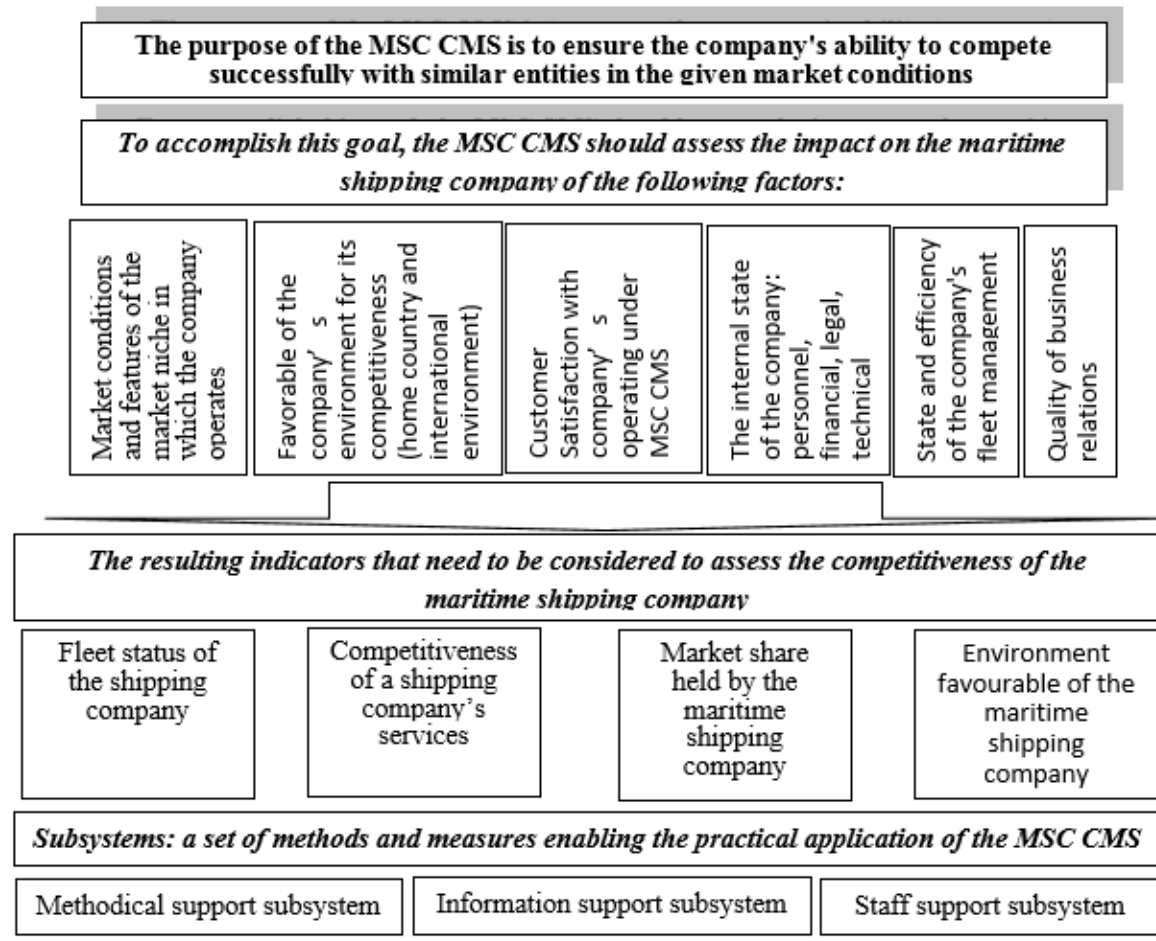

Thus, for the stable functioning of the MC MCM system, the interaction of three subsystems is necessary: methodological support, information support and personnel support.

Considering the competitiveness management system of a maritime shipping company as an object of research in the framework of this work, at first it is necessary to identify and describe the main properties of such a system (Figure 3 ).

${ }^{4}$ Compiled by the authors on the materials of the study. 
Figure 3. MSC CMS features ${ }^{5}$ Features

\section{Comment}

System universality
The MSC CMS should simultaneously analyze data on
all aspects of the company activities, including
quantitative and qualitative indicators

\begin{tabular}{|c|c|}
\hline System flexibility & $\begin{array}{l}\text { The system shall be integrated into the existing } \\
\text { management system of the maritime shipping company }\end{array}$ \\
\hline $\begin{array}{c}\text { The relative nature of the } \\
\text { system }\end{array}$ & $\begin{array}{l}\text { Competitiveness of a company acquires practical sense } \\
\text { only in comparison with competing companies. } \\
\text { Accordingly, the effectiveness of the applied system } \\
\text { cannot be adequately evaluated in the absence of } \\
\text { relevant information about competing organizations }\end{array}$ \\
\hline $\begin{array}{l}\text { System focused to meet } \\
\text { customer requirements }\end{array}$ & $\begin{array}{l}\text { The shipping company provides transportation services, } \\
\text { which means that, first of all, the company's } \\
\text { competitiveness depends on the degree of customer } \\
\text { satisfaction. Hence the the competitiveness management } \\
\text { system shall be customer focused }\end{array}$ \\
\hline $\begin{array}{l}\text { The dependence of the } \\
\text { company's total } \\
\text { competitiveness on the } \\
\text { competitiveness of its fleet }\end{array}$ & $\begin{array}{l}\text { The maritime shipping company, working in the service } \\
\text { sector, nevertheless bases its activities on the operation } \\
\text { of sea cargo vessels. Such vessels, demanding colossal } \\
\text { investments and being the only means of production, } \\
\text { bring the business of the maritime shipping company } \\
\text { closer to the husiness nrocess of indistrial enternrises }\end{array}$ \\
\hline
\end{tabular}

To develop a competitiveness management system for a maritime shipping company, at first it is necessary to correctly determine its requirements. Desired system should:

1) characterize the competitiveness of the shipping company in all aspects of its operations;

2) provide the necessary analytical (including forecast (Kurenkov and Nekhaev, 2012)) information for the management of the company;

3) have a mechanism for rapid response to changes in the internal and external environment of the maritime shipping company;

4) provide an opportunity to compare the company's competitiveness indicators with similar indicators of competing organizations and, accordingly, to create a competitiveness rating of maritime shipping companies;

${ }^{5}$ Compiled by the authors on the materials of the study. 
5) have compatibility with the systems and methods of performance management applied in the company.

The universality of the MSC CMS is a constant requirement for systems of such type. Analysis of the company's activity as a whole, and not of its individual aspects, implies operating with heterogeneous source data: information about the fleet's technical condition, the effectiveness of commercial management, the availability and movement of personnel, and the financial sustainability indices necessary for analyzing all aspects of the company's activities.

The integrity of the MSC CMS is expressed primarily in the fact that in order to correctly analyze the position of a company in a competitive environment, it is necessary to consider both the external and internal environment of activity inextricably. The influence of external environmental factors requires the company to change the internal environment. In their turn, the features of the company's business processes form the weak and strong points in the competitive position of the organization.

The adaptability of the system is an absolutely necessary feature of it when working in market conditions with fast and significant fluctuations in the market situation (Svetunkov, 1997). As an example competent commercial operation of its own fleet is traditionally more profitable than time-charter, however, if a sharp decline in demand for tonnage in a particular market segment is expected, the time-chartering of your own fleet for such an unstable period can bring the company more income.

The hierarchical principle of building a system implies that it is sufficiently informative at any level, starting from groups of auxiliary indicators characterizing a specific aspect of a company's activity, ending with the integral indicators (Winn and Holden, 1981) of competitiveness. Thus, it becomes possible to trace the reasons for the growth or decline of the company's competitiveness and introduce the necessary corrective changes in the business process.

The flexibility of the system implies its applicability in any shipping company - from mini-companies operating one vessel to large corporations with a fleet of tens of units. In both cases, the implementation of the system should not disrupt the established business process and an established system of relations in the organization, as well as not to interfere with the implementation of previously implemented specialized systems: personnel management, security management, and others.

The relative nature of the system, as follows from the definition of competitiveness, implies the usefulness of the system being created only if there is sufficient information about the activities of competing companies. Without having comparative data for the study, it is impossible to determine whether the use of the 
MSC CMS have a favorable influence for the company, and also the results of the implementation of such a system are incomprehensible.

The focus of the system on meeting the customer requirements is due to the service nature of services provided by maritime shipping companies (Gissin and Mitko, 2012). A sea carriage service, like any other service, cannot be accumulated or improved; it can only be rendered at a certain price with a certain quality. Considering that the consumer of the service is usually the governments of the countries or large industrial and agricultural companies, the usual methods of attracting customers - advertising campaigns, cold calls and others - have no sufficient effect.

The dependence of the company's competitiveness on the competitiveness of the fleet brings the maritime shipping company closer to industrial enterprises. Sea vessels are very expensive equipment, designed for decades of operation and requiring significant material, financial and human resources to maintain proper condition. The provision of services through a rented fleet is possible, but somehow the ship is the only means of production for the shipping company, and the company's competitiveness ultimately depends on the competitiveness of each vessel.

Describing systems, it is necessary to take into account that their synergy is an inherent property. In other words, the system as a whole has some unique properties that all elements that do not possess it (Zhilin, 2004). The presence of synergy is a reliable confirmation of the presence and effectiveness of the system.

According to authors, the synergistic effect of the competitiveness management system of a maritime shipping company should be its ability to provide such a company with a competitive advantage in the market under constant initial conditions.

\section{Conclusion}

The competitiveness management system of the maritime shipping company should be harmoniously integrated into the company's existing business processes and not require the involvement of significant resources for the assessment. For the best assessment of competitiveness, it is necessary to carry out observations over a long period of time and observe the dynamics of changes in the values of indicators, while today most experts from consulting firms are involved in researching the company's business processes once. The assessment is based on a set of auxiliary indicators reflecting certain aspects of the company's activities and then combined into a single, hierarchical system that allows to calculate the value of a generalized indicator of competitiveness necessary for comparing a company with its competitors. 
The functioning of the competitiveness management system is based on the operation of three supporting subsystems (methodological support, information support, staffing). This will allow introducing a competitiveness management system into the maritime shipping company without changing existing business processes and with minimal time and resources. The main differences of the proposed concept from the existing ones are: consideration of the specifics of the activities of maritime transport; orientation of the system to comparison with competing companies. The developed concept can serve as a basis for further development of research on the study of competitiveness in relation to companies operating in the global freight market.

The main differences of the proposed concept from the existing ones are: consideration of the specifics of the activities of maritime transport; orientation of the system to comparison with competing companies. The developed concept can serve as a basis for the further development of research on the study of competitiveness in relation to companies operating in the global freight market.

\section{References:}

Gissin, V.I., Mitko, O.A. 2012. Analysis of the transport and logistics service in customer service. Accounting and statistics, 25.

Ha, Y.S., Seo, J.S. 2017. An analysis of the Competitiveness of Major Liner Shipping Companies. The Asian Journal of Shipping and Logistics, 2(33), July.

Kurenkov, P.V., Nekhaev, M.A. 2012. Application of foresight technologies in the management of economic processes in transport. Economics of Railways, 3.

Svetunkov, S.G. 1997. Forecasting the economic situation in marketing research. SaintPetersburg, Peter publ.

Tenold, S., Ojala, J. 2017. How to Sail a Sinking Ship: Adapting to the Declining Competitiveness of the European Shipping Industry. Routledge: Industries and Global Competition: A History of Business Beyond Borders.

Thalassinos, I.E., Stamatopoulos, V.T. and Arvanitis, E.S. 2011. Gender wage gap: Evidence from the Hellenic maritime sector 1995-2002. European Research Studies Journal, 14(1), 91-101.

Winn, R., Holden, K. 1981. Introduction to Applied Econometric Analysis. Moscow, Finance and statistics publ.

Zhilin, D.M. 2004. Systems Theory. Moscow, URSS, p. 183. 